\title{
Prescription information leaflets: a pilot study in general practice
}

\author{
C F GEORGE，W E WATERS，J A NICHOLAS
}

\begin{abstract}
Leaflets containing information about medicines were issued to 56 patients prescribed penicillins and 43 patients prescribed non-steroidal anti-inflammatory drugs. The patients were interviewed between four and 10 days later and their responses compared with those of 65 patients prescribed penicillin and 33 prescribed nonsteroidal anti-inflammatory drugs who did not receive a leaflet. Patients who received a leaflet were more likely to be completely satisfied with their treatment and with the information they had been given. They were also more likely to know the name of their medicine and much more aware of potential unwanted effects. Although there was no evidence that knowledge increased the incidence of adverse effects, when these did occur they were more likely to be recognised as being due to the medicine. Further studies of other leaflets are warranted, including leaflets for drugs that are taken long term.
\end{abstract}

\section{Introduction}

To use medicines properly patients require certain basic information. Doctors and pharmacists may not have time, however, to explain drug actions to individual patients, and

University of Southampton, Southampton

C F GEORGE, MD, FRCP, professor of clinical pharmacology

W E WATERS, MB, FFCM, professor community medicine

J A NICHOLAS, BA, research assistant

Correspondence to: Dr C F George, Clinical Pharmacology Group, University of Southampton, Medical and Biological Sciences Building, Bassett Crescent East, Southampton SO9 3TU. when they do the language they use may be misunderstood. Furthermore, verbal advice is often forgotten or ignored by patients for several reasons, including anxiety. Clear labelling and counselling may overcome some of these problems, but the space available for labels is limited and verbal advice may be forgotten unless reinforced.

Studies from abroad have shown that written information can help patients to understand and comply with their doctor's advice. ${ }^{1-4}$ Few studies have been carried out in the United Kingdom; most have been on small numbers of patients and usually in hospital practice. ${ }^{5-7}$ In the present pilot study we examined the effects of supplying written information on penicillins and non-steroidal anti-inflammatory agents on the attitudes and knowledge of patients attending two general practices in Southampton and south west Hampshire.

\section{Methods}

The study was approved by the local ethics committee.

Prescription information leaflets-Information leaflets were prepared for penicillins and non-steroidal anti-inflammatory drugs by members of a steering group.* The written information (figs 1 and 2) included the name of the drug, its nature, purposes, contraindications, and precautions to be taken; instructions about correct dosage, what to do if a dose was missed, possible unwanted effects, and the action to take if any of these were experienced; and advice on proper storage conditions and what action to take in the event of an overdose. The

* Members of steering group were: Professor D R Laurence (chairman) (London); Professor C Fletcher (London); Professor C F George (Southampton); $\mathrm{Mr} \mathrm{S}$ Steele (London); Professor W E Waters (Southampton); Dr M Goodman (vice Dr F Wells) (BMA); Mr D W Feesey (Department of Health and Social Services); $\mathrm{Mr} \mathrm{N} M$ Hale (vice Mr R N Williams) (Department of Health and Social Services); Mr B H Hartley (Department of Health and Social Services); Dr E S Snell (Association of British Pharmaceutical Industry); $\mathrm{Mr} J$ Wyatt (Disabled Living Foundation); Dr C F Donovan (Royal College of General Practitioners); Mr D N Sharpe (Pharmaceutical Society of Great Britain). 
leaflets were style edited ${ }^{8}$ by $\mathrm{Mr} \mathrm{K}$ Cripwell (University of London Institute of Education) for more effective communication.

Patients-One hundred and ninety seven patients (73 male; 124 female) were seen after they had been prescribed a penicillin or non-steroidal anti-inflammatory drug. Two practices took part in the study: one had surgeries in Brockenhurst and Sway and the other in Southampton. Ninety five patients were drawn from the Brockenhurst and Sway practice and 102 from that in Southampton. Patients were asked at the consultation for consent to an interview later.

Procedure-Leaflets were issued during alternate weeks, but the names and addresses of all patients prescribed either a penicillin or a non-steroidal anti-inflammatory drug were recorded so that a control group was available who did not receive an information leaflet. In Brockenhurst and Southampton the leaflets were issued by the general practitioners, whereas in Sway they were issued from the nearby pharmacy. Patients were contacted and interviewed by a research assistant between four and 10 days later. A questionnaire was administered to the patient (in the case of children born after

\section{PENICILLINS}

Please read this carefully before you start to take your medicine. If you have any questions or are not sure about anything ask your doctor or chemist.

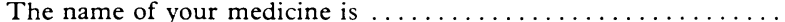
This is one in a group of medicines called penicillin. Penicillin kills germs which cause infections in your body.

Has anyone told you you are allergic to penicillin? If so, tell your doctor or chemist. You can then be given another medicine instead of penicillin.

If you are breast-feeding tell your doctor so that you can be given another medicine instead of penicillin because penicillin may pass through your milk and harm your baby.

Keep all medicines out of the reach of children.

\section{Times to take medicine}

You must take this medicine regularly. The label will tell you when to take your medicine. It will also tell you how much to take. Ask your doctor or chemist if you are not sure.

This medicine works best with water when your stomach is empty. This is one hour before a meal or 2 hours after a meal. But sometimes your doctor will tell you to take it at other times. Look carefully at the label.

If the medicine is for a baby the best time to give it is between feeds.

Keep taking your medicine until it is finished. Don't stop just because you feel better. The medicine may not have killed all the germs. If you stop too soon they may start up the infection again.

If you forget to take a dose take another as soon as you remember.

Then go on as before.

Shake all liquid medicines well before you take a dose.

\section{After taking the medicine}

A few people can be upset by this medicine. They have frequent loose bowel motions or feel like being sick. If you suffer from either of these very badly, or you vomit the medicine tell your doctor.

Tell your doctor if you START suffering from any of the following things:

Rashes or itching, or any other skin trouble

Wheezing

Pain in your joints for the first time

Tell your doctor about any other unusual problems as soon as you can.

\section{Storage}

Keep capsules and tablets in a cool, dry place. Keep them in a safe place where children can't get them. Your medicine could harm them.

Keep liquid penicillin in the refrigerator but not in the freezer compartment. Pencillin lasts only a few days in the refrigerator. The label will tell you how long. Don't take this medicine after this date. Flush any left-over medicine down the toilet or return it to the chemist unless your doctor or chemist tells you to keep it.

\section{Your medicine}

This medicine is for YOU. Only a doctor can prescribe it for you. Never give it to someone else. It may harm them even if the symptoms are the same as yours.

FIG 1-Information presented in penicillin leaflet.

\section{ANTI-INFLAMMATORY ANALGESICS}

Please read this carefully before you start taking the medicine. If you have any questions or are not sure about anything, ask your doctor or chemist.

You have been given.

This medicine can relieve inflammation, joint pains and pain due to arthritis and rheumatism.

\section{Warning}

This medicine has been prescribed by the doctor and is only for YOU. Do NOT give it to anyone else with the same sort of symptoms because it may harm them. Keep all medicines out of the reach of children.

Some questions

* Are you already taking aspirin or another drug used to treat arthritis?

* Have you ever had an allergic reaction or wheezing after taking aspirin?

* Have you experienced stomach discomfort, felt like being sick or had heartburn after taking aspirin?

* Have you had a stomach ulcer previously?

* Are you on medicines for thrombosis (e.g. warfarin) or gout?

* Are you pregnant?

If the answer is $Y e s$ to any of these questions, tell your doctor or chemist.

\section{Taking your medicine}

Take your medicine at the correct times. The label will show you how much to take and how often. If it doesn't or you are not sure, ask your chemist or doctor.

Keep taking your medicine until it is finished unless your doctor tells you to stop. Do not stop just because you feel better.

Normally, tablets or capsules should be swallowed with a glass of water or milk. But soluble tablets must be dissolved in water before you take them.

\section{When taking the medicine}

If you forget to take a dose take another as soon as you remember. Then go on as before.

Although most people benefit from taking this medicine it has sometimes caused side-effects. If you get any of the following, tell your doctor as soon as possible:

Stomach discomfort or heartburn for the first time

You vomit blood or pass tarry stools

You should also tell your doctor if you develop any of the following for the first time:

Skin trouble, such as a rash or itching

Wheezing

Ringing in the ears or dizziness

Store the medicine in a cool, dry place (out of the reach of children). Some medicines deteriorate with time so do not keep them for longer than you need to.

Flush any left-over medicine down the toilet or return it to the chemist unless your doctor or chemist tells you to keep it.

In the event of accidental overdose, contact your nearest hospital casualty department or tell your doctor immediately.

FIG 2-Information presented in leaflet on non-steroidal anti-inflammatory drugs.

1967 a parent or guardian answered the questions) which sought responses on the overall opinion on the leaflet (when relevant) and satisfaction with information given and treatment in general; and knowledge of the name of the drug, its purposes, and potential unwanted effects. Compliance was assessed both by questions and by tablet counts. Patients were asked also about storage and disposal of their medicines. Proportions were compared statistically using the $\chi^{2}$ test with Yates's correction.

\section{Results}

Opinion on the leaflets-Overall opinion on the leaflets was favourable: only one patient out of 99 said his leaflet was not clear. Table I gives a more detailed breakdown of these results. Thirty five of the patients found the penicillin leaflet either "helpful" or "very helpful," but 16 thought it unnecessary; four patients had not read the leaflet by 
the time of interview. Forty three patients received the information leaflet on non-steroidal anti-inflammatory drugs, of whom two had not read it at the time of interview. Twenty seven patients $(66 \%)$ found the leaflet "helpful" and four "very helpful." Only eight patients $\left(20^{\prime \prime}{ }_{10}\right)$ thought it unnecessary. Unlike with the penicillin leaflet (which none of the patients found worrying), seven of the patients $\left(17^{\prime \prime}\right)$ who read the leaflet on the non-steroidal antiinflammatory drugs found it "a little worrying."

TABLE I-Patients' reactions to prescription information leaflets

\begin{tabular}{|c|c|c|}
\hline & $\begin{array}{l}\text { Penicillin leaflets } \\
(n=56)^{*}\end{array}$ & $\begin{array}{c}\text { Non-steroidal anti-inflammatory } \\
\text { drug leaflets }(n=43)^{+}\end{array}$ \\
\hline \multicolumn{3}{|l|}{ Clarity: } \\
\hline $\begin{array}{l}\text { Very clear } \\
\text { Clear } \\
\text { Unclear } \\
\text { Confusing }\end{array}$ & $\begin{array}{r}34(65) \\
17(33) \\
1 \quad(2)\end{array}$ & $\begin{array}{r}33(81) \\
8(20)\end{array}$ \\
\hline \multicolumn{3}{|l|}{ Usefulness: } \\
\hline $\begin{array}{l}\text { Very helpful } \\
\text { Helpful } \\
\text { Unnecessary } \\
\text { Unhelpful } \\
\text { Harmful }\end{array}$ & $\begin{array}{r}2(4) \\
33(64) \\
16(31) \\
1 \quad(2)\end{array}$ & $\begin{array}{r}4(10) \\
27(66) \\
8(20) \\
2(5)\end{array}$ \\
\hline \multicolumn{3}{|l|}{ Reaction: } \\
\hline $\begin{array}{l}\text { Very reassuring } \\
\text { Reassuring } \\
\text { Neutral } \\
\text { A little worrying } \\
\text { Very worrying }\end{array}$ & $\begin{array}{r}19(37) \\
31(60) \\
1 \quad(2)\end{array}$ & $\begin{array}{r}19(46) \\
15(37) \\
7(17)\end{array}$ \\
\hline Don't know & 1 (2) & \\
\hline
\end{tabular}

*Four of the 56 did not read their leaflet.

+ Two of the 43 did not read their leaflet.

TABLE $1 \mathrm{I}-$ Knowledge of side effects (figures are numbers $(\%)$ of patients)

\begin{tabular}{lcc}
\hline & Given leaflet & Not given leaflet \\
\hline & Penicillin & \\
n & 56 & 65 \\
Wheezing & $17(30)$ & $2(3)$ \\
Skin trouble & $44(79)$ & $31(48)$ \\
Vomiting & $25(45)$ & $13(20)$ \\
Pain in joints & $6(29)$ & $3(5)$ \\
Cold or numb fingers* & $1(2)$ & $1(2)$ \\
\multicolumn{1}{c}{ Non-steroidal anti-inflammatory drugs $^{*}$} \\
n & 43 & 33 \\
Wheezing & $29(67)$ & $3(9)$ \\
Ringing in ears & $24(56)$ & $3(9)$ \\
Heartburn or stomach ache & $23(54)$ & $8(24)$ \\
Dizziness or unsteadiness & $23(54)$ & $6(18)$ \\
Increased depression* & $1(2)$ & $1(3)$ \\
& & \\
\hline
\end{tabular}

*These side effects were not mentioned in leaflets.

Patient satisfaction-For both types of drugs studied patients who received a leaflet were more likely to be "completely satisfied" with their treatment $(64 \%(36 / 56) v 52 \%(34 / 65)$ for penicillins and $72^{\circ} \%(31 / 43) v 58^{\circ} \%(19 / 33)$ for non-steroidal anti-inflammatory drugs), but the differences were not significant. Patients who received a leaflet were more likely to be satisfied with the information they received: among those taking penicillins 63\% (35/56) of those who received a leaflet were completely satisfied compared with $34 \%$ $(22 / 65)$ of the controls $(p=0.05)$. Among those taking non-steroidal anti-inflammatory drugs the figures were $47 \%(20 / 43)$ and $18 \%$ (6/33) respectively $(p<0 \cdot 05)$.

Knowledge-Knowledge of the name(s) of the drug(s) being taken was greater among patients who had received a leaflet. Among those taking penicillins 52 patients $(91 \%)$ who received a leaflet could name their drug correctly compared with $48(75 \%)$ of those who did not $(p=0.06)$. Among the patients who received a non-steroidal antiinflammatory $37\left(86^{\circ}\right)$ ) of those who received a leaflet knew the name of their medicine compared with $18\left(55^{\circ}\right)$ of those who did not $(\mathrm{p}<0.01)$. Although a higher proportion of patients who received a leaflet about penicillins were aware of the purpose of the medicine, the difference did not achieve significance. More than $90 \%$ of all patients who received a non-steroidal anti-inflammatory drug were aware of its purpose, so the leaflets had no obvious effect in this respect. Patients who received a leaflet on penicillins were sig- nificantly more aware of the nature of possible unwanted effects including wheezing, vomiting, and joint pains (table II). They were also aware that depression might be a side effect, although this was not mentioned in the leaflet. Among patients taking non-steroidal anti-inflammatory drugs those who received a leaflet were far more aware of the possible occurrence of wheezing, dizziness, vomiting, heartburn, skin trouble, and ringing in the ears. No excess of false positive responses was seen.

Compliance-There was no difference in awareness of instructions relating to the taking of medicines between those patients who received a leaflet and those who did not. A higher proportion of patients who did not receive a leaflet on penicillins, however, omitted doses $(31(48 \%))$ than those with a leaflet $(14(25 \%) ; \mathrm{p}<0.05)$. Among those taking non-steroidal anti-inflammatory drugs the findings were reversed : $49 \%$ of those who received a leaflet omitted doses compared with $36 \%$ of controls (NS).

Safety-Patients were asked what they would do with any medicines that they had left over. A correct response was either that they would flush them away down the lavatory or take them back to the chemist. The penicillin leaflet apparently had no effect on disposal, whereas that on non-steroidal anti-inflammatory drugs appeared to have a positive effect $(67 \%$ correct compared with $36 \%$; p < 0.05$)$.

Other effects-Patients who had a leaflet were no more likely to experience or report adverse effects than those who did not. Thirty three patients $(28 \%)$ taking a penicillin experienced one or more unwanted effects. Of the total of 40 adverse effects that occurred, 18 were experienced by patients who had received a leaflet. With non-steroidal anti-inflammatory drugs a total of 34 adverse effects occurred among 22 patients. Twenty of them affected patients who had received a leaflet and 14 the control group (NS). Although patients who received a leaflet were not more likely than the control group to report adverse effects to their doctors, they were more likely to connect what they had experienced with their medicine. This was particularly noticeable among patients taking non-steroidal antiinflammatory drugs: $90 \%$ of the adverse effects were attributed to the medicine by patients who had received a leaflet compared with $57^{\circ}$ of the symptoms among the control group $(\mathrm{p}<0.05)$.

Doctors' reactions-The general practitioners thought the principle of giving information a good one. Several, however, found it difficult to remember to issue leaflets at the time of seeing and prescribing for patients. It was thought that the storage (and issue) of leaflets might be difficult if these and others were in routine use. The Southampton doctors thought the handouts too long for most patients to read through and absorb.

\section{Discussion}

The needs of patients in relation to information about prescribed medicines have been specified by Herman and colleagues. ${ }^{9}$ The leaflets that we prepared met all but one of their suggestions. We decided against including information about what to do if the medicine appeared not to work because many patients were due to be reviewed and we believed that others would consult their doctors if their symptoms failed to respond.

Our leaflets differed from many others in that they were of a generic type and designed to be informative rather than to protect against possible litigation. Thus although the incidence of adverse effects differs between non-steroidal anti-inflammatory drugs, this was not stated in the leaflets. Secondly, after review within the steering group the leaflets were translated into simple language that appears to have been intelligible to almost all patients. The final, important step in preparing our leaflets was that they were tested on patients before being issued. Although this had no effect on their content, it led to modifications in the order and presentation of information.

These leaflets appear to have been beneficial in several ways. Firstly, satisfaction with the information received (and treatment in general) was higher among the patients who received a leaflet. Secondly, patients prescribed penicillins were more likely to complete the course if they had been given a leaflet. Thirdly, knowledge about medicines, particularly of their potential unwanted effects, was significantly increased. For some patients, however, leaflets carried no benefit as the patients either thought them unnecessary or did not bother to read them. This probably reflects the fact that $75(62 \%)$ of the 
patients remembered having taken a penicillin before and at least half of those prescribed a non-steroidal anti-inflammatory drug had taken one previously.

Although our study was larger than previous ones performed in this country, the number of patients studied was too small for us to draw conclusions on some items. For example, it is noteworthy that seven patients who received a leaflet on nonsteroidal anti-inflammatory drugs found it "a little worrying" and that compliance with treatment was slightly lower in this group. A larger study is necessary in order to confirm (or refute) these findings, and we hope to carry this out. In addition, we intend to look at the long term effects of information given for medicines such as beta adrenoceptor antagonists, diuretics, and bronchodilators, which tend to be used chronically.

We thank the Wessex Regional Health Authority for the financial support of this project; the patients who participated in the study; and Miss P Jepson and Miss D Rainbow for distributing the leaflets in Sway.

The practices that took part in the study were Brockenhurst and Sway (Drs B J Stevenson, T J M Horsfall, D S Browne, and Dilys Jones) and Southampton (St James) (Drs A H Laxton, G P Coleman, W P Munro, D B Percy, and P Pritchard).

\section{References}

${ }^{1}$ Fleckenstein L, Joubert P, Lawrence R, Patsner B, Mazzullo JM, Lasagna L. Oral contraceptive patient information. A questionnaire study of attitudes, knowledge and preferred information sources. FAMA 1976; 235:1331-6.

2 Morris LA, Halperin JA. Effects of written drug information on patient knowledge and compliance: a literature review. Am $\mathcal{f}$ Pub Health $1979 ; 69: 47-52$

${ }^{3}$ Eklund LH, Wessling A. Evaluation of package enclosures for drug packages. Lakartidningen 1976;73:2319-20.

${ }^{4}$ Institute of Medicine. Evaluating patient package inserts. Washington: National Academy of Sciences, 1979.

${ }^{5}$ Ellis DA, Hopkin JM, Leitch AG, Crofton J. Doctors' orders: controlled trial of supplementary written information for patients. $\mathrm{Br}$ Med f $1979 ; \mathrm{i}: 456$

${ }^{6}$ Ley P, Jain VK, Skilbeck CE. A method for decreasing patients' medication errors. Psychological Med 1976;6:599-601.

${ }^{7}$ Myers ED, Calvert EJ. Knowledge of side effects and perseverance with medication. Br 7 Psychiatry 1978;132:526-7.

${ }^{8}$ Cripwell KR. Computer assisted style editing of English language medical texts for readers in developing countries. Fournal of Research and Communication Studies $1981 ; 3: 281-8$

${ }^{9}$ Herman F, Herxheimer A, Lionel NDW. Package inserts for prescribed medicines: what minimum information do patients need? $\mathrm{Br}$ Med $\mathcal{f}$ $1978 ;$ ii :1132-5.

(Accepted 1 August 1983)
क

垔

음

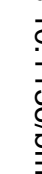

ज.

\section{MATERIA NON MEDICA}

\section{Small change}

As a reluctant administrator I learnt with some interest that I was to be a member of the newly formed unit management team. As I understood it, the recent reorganisation of the NHS had been to shake out the dead wood on the administrative and nursing sides and to devolve decision making from the district level to the unit. I was therefore looking forward to being part of a dynamic management team with responsibility for a budget of about $£ 11$ million.

At the first meeting of the team I was a little surprised at the youthfulness of my colleagues but they seemed confident and were well versed in a jargon which I was obviously going to have to learn before I could have any "meaningful dialogue." The next event was a meeting of all the teams in the district under the chairmanship of the district administrator, at which it was made clear to us that virement (movement of moneys) between the various budgets of a unit was not to be allowed. This seemed to negate our role as local managers, since once we had got our money for the unit we were evidently going to have to be very skilful in dividing it up fairly among the competing budgets as any redistribution would be difficult. The other interesting happening that evening was a sort of management game in which these highly selected managers declared how they saw their role in the system, something I had assumed had been decided before reorganisation.

Then the budget arrived. This was not as I had expected, in a lump sum of $£ 11$ million to be divided up at the unit managers' discretion, but had already been scrupulously allocated exactly as in the previous year, with a paltry increase for inflation and a $1 \%$ reduction for efficiency savings. Since last year's budgets had without exception been insufficient, it seems inevitable that this year's will also be too small and the possibility of virement will not arise. In effect the unit management team has no control over the budget and is therefore strictly limited in its powers.

What, then, does the team do at its lengthy weekly meetings? Well, it talks about the day to day "housekeeping" of the unit. This is identical to the discussions in the old hospital management team, of which I was a member before reorganisation, except that community problems are included. Any decisions taken are inevitably also at this level.

Has anything therefore changed as a result of the recent reorganisation? So far as I am concerned, very little; true, we do have an accountant attending our meetings to explain why there is no spare money, but otherwise things are much as before. The staff, of course, have changed at a considerable personal cost in terms of stress and loss of morale. The older and more experienced administrators have sensibly taken early retirement and there has been a general loss of the identification and commitment so necessary for a happy and efficient hospital.
So is it necessary to have a doctor on the team at all if decisions are only to be made at a low managerial level? Reluctantly I think he should hold a watching brief for the patients and the doctors, although it is obviously an inefficient use of medical time.

At this stage there is little reason to applaud the latest NHS reorganisation. The principles are sound but the skill to apply them seems lacking. Unless unit management teams are composed of managers capable of administering the enormous budgets, control will remain centralised and the exercise will founder.-JULIAN NEELY, consultant surgeon, Sussex.

\section{An unconventional landing}

To be asked to play squash for a team is an accolade that I rarely refuse simply because it does not happen very often; and to be told that travelling expenses by air would be paid made me feel $I$ had really arrived on the local squash scene. Moreover, the return trip was to be in a plane especially chartered for the team.

This flight had the essential ingredient of "VIP" treatment-the airport being especially opened for the occasion, as on Sundays it is usually shut. All the passengers were weighed, the ladies even plane and we carried our own luggage aboard. The pilot asked me if I would like to sit in the copilot's seat, an offer I could not refuse. Just before take off he asked, "Where are we going ? Is it Castletown?" I replied in the affirmative, delighted to be useful as a copilot.

Having confirmed our destination, we were off across the Pentland Firth on our 15 minute flight. I was given a map to show the direction in which we were heading. At $500 \mathrm{ft}$ all the landmarks are clearly visible-so much more reassuring than jetting through the ubiquitous blue sky at $33000 \mathrm{ft}$. As we approached our destination, the pilot pointed out the airstrip: a disused, semiconcrete piece of ground used as pasture by the local cows and sheep. The plane circled low round the area to drive away the herd of cows before we came down to a perfect landing. As we taxied to a halt I was startled by the violent sound coming from the plane-a honk: I hadn't realised that aeroplanes had horns. In this case the cows obeyed the warning and stayed out of the way. We stepped straight from the aircraft on to the ground, treading warily to avoid the cow pats and sheep droppings. The pilot, after bidding us goodbye, had to spend a few minutes chasing the curious cows away before taking off.

Squash matches, especially those away from home, are remembered for many reasons, not least for the amount of alcohol consumed and other post match revelry. But for me, in spite of the result of the match, the trip was memorable if only for the unconventional landing. -PRADIP K DATTA, consultant surgeon, Wick, Scotland. having to get on the scales with their handbags. It was an eight-seater 